\title{
SOSIALISASI BLENDED LEARNING DALAM PEMBELAJARAN BAHASA INGGRIS
}

\author{
Elyza Martiarini $^{1)}$, Asti Ramadhani Endah Lestari ${ }^{2)}$ \\ Prodi Pendidikan Bahasa Inggris, Fakultas Bahasa dan Seni, \\ Universitas Indraprasta PGRI
}

\begin{abstract}
Abstrak
Tujuan pada kegiatan pengabdian kepada masyarakat ini adalah memberikan sosialisasi pembelajaran Blended Learning era revolusi 4.0 untuk para guru atau tenaga pengajar di Yasporbi III. Dalam hal ini sosialisasi yang diberikan dititikberatkan pada penggunaan aplikasi Google Classroom. Model pembelajaran blended learning dapat bermanfaat untuk meningkatkan fleksibiklitas dan efektifitas pembelajaran. Kegiatan sosialisasi ini memberikan pengetahuan kepada seluruh peserta bahwa banyak sekali Learning Management System yang bisa digunakan untuk mendukung pembelajaran berbasis media digital bertemakan Blended Leaning yang sangat sesuai dengan perkembangan era disruptif ini.

Kata kunci: Blended Learning, Google Classroom, LMS

Abstract

The aim of this program is to provide socialization of Blended Learning in the revolutionary era 4.0 for the teachers or instructors at Yasporbi III. The program focused on training the teacher on how to use Google Classroom application. The advantage of Google Classroom application lies on the flexibility and effectiveness of learning. This socialization activity provided knowledge to all participants about Learning Management Systems that could be used to support digital media-based learning with the theme of Blended Leaning which is very suitable for the development of this disruptive era.
\end{abstract}

Key words: Blended Learning, Google Classroom, LMS

Correspondence author: Elyza Martiarini, elyza.martiarini@unindra.ac.id; Jakarta, Indonesia.

\section{PENDAHULUAN}

Kegiatan belajar mengajar di era revolusi industri 4.0 merupakan konsep belajar terpadu yang melibatkan kemampuan kognitif, afektif, dan psikomotorik, serta kemampuan literasi digital dalam memperoleh dan mengolah informasi secara daring berdasarkan perkembangan ilmu pengetahuan dan teknologi informasi secara menyeluruh.

Menghadapi tantangan besar di era inovasi disruptif ini, masa di mana inovasi berkembang sangat cepat, pemanfaatan teknologi digital dalam proses pembelajaran yang dikenal dengan sistem siber (cyber system) mampu membuat proses pembelajaran berlangsung secara kontinu tanpa batas ruang dan waktu. Guru sebagai garda terdepan dalam dunia pendidikan harus senantiasa meng-upgrade kemampuan serta kompetensi 
dirinya menghadapi pendidikan di era 4.0 karena yang dihadapi saat ini adalah siswa yang merupakan generasi milenial yang dalam kehidupan kesehariannya sudah tidak asing lagi dengan dunia digital, sudah terbiasa dengan arus informasi yang demikian cepat bahkan kemampuan siswa saat ini dalam mengakses informasi dikatakan lebih uptodate.

Mengingat tantangan besar di atas, guru harus terus menerus belajar meningkatkan kompetensi serta aktualisasi diri terhadap perkembangan ilmu pengetahuan dan teknologi digital serta menciptakan kegiatan belajar yang digital pula, menggeser kegiatan konvensional dengan metode yang lebih atraktif, unggul, paperless, pemberian tugas secara daring, dan ruang belajar yang tak berbatas.

Salah satu yang menjadi faktor penghambat dalam peningkatan kualitas pembelajaran di era pendidikan 4.0 adalah kurangnya penguasaan pemanfaatan teknologi digital yang disebabkan oleh intensitas penggunaan pembelajaran secara digital yang masih rendah. Guru masih mendominasi pengetahuan dan pembelajaran masih dilakukan secara konvensional. Guru juga belum memiliki kemampuan yang mumpuni dalam hal pemanfaatan media belajar daring.

Hal ini juga diungkapkan dalam wawancara singkat dan sederhana yang dilakukan terhadap Kepala Sekolah Yasporbi III. Yasporbi III merupakan sebuah sekolah swasta umum yang menyediakan program pendidikan sesuai dengan kurikulum Nasional yang dikembangkan dengan mengintegrasikan ilmu pengetahuan dan teknologi (Iptek) dengan peningkatan keimanan dan ketakwaan. Hasil wawancara singkat menunjukkan bahwa para guru mengalami kesulitan dalam melaksanakan kegiatan pembelajaran blended learning, para guru menginginkan sebuah media yang memudahkan baik guru maupun siswa dalam berinteraksi di luar tatap muka dalam kelas. Guru membutuhkan sebuah ruang kelas yang bersifat daring sehingga bisa digunakan siswa untuk mengakses bahan ajar, tugas mandiri, serta forum diskusi kelas di luar jam pelajaran sekolah.

Dewasa ini, sumber belajar tidak hanya selalu bersumber pada buku, modul, atau bahan ajar cetak lainnya yang biasa digunakan pada pembelajaran konvensional. Memasuki era revolusi industry 4.0, pendidikan merupakan salah satu bidang yang berimbas langsung dimana sistem atau teknik belajar konvensional mengalami revolusi ke arah digital berbasis elektronik dan internet (e-learning). Model pembelajaran $e$ learning dapat bermanfaat untuk meningkatkan fleksibiklitas dan efektifitas pembelajaran. Dengan e-learning, materi dapat diperkaya dengan berbagai sumber belajar termasuk multimedia dengan cepat dapat diperbaharui oleh pengajar. (Maryani, 2013)

Blended learning adalah metode pembelajaran yang menggabungkan antara metode konvensional (tatap muka) di kelas dan pembelajaran secara online. Menurut Thorne (dalam Sjukur, 2012: 370) blended learning adalah kesempatan untuk mengintegrasikan inovasi dan teknologi yang ditawarkan oleh pembelajaran daring dengan interaksi dan partisipasi pembelajaran konvensional. Kegiatan blended learning ditandai dengan menggabungkan pembelajaran konvensional dan daring. Penggabungan pembelajaran disesuikan dengan tujuan pembelajaran yang hendak dicapai.

Salah satu media pembelajaran yang termasuk ke dalam blended learning adalah Google Classroom. Aplikasi yang merupakan buatan Google ini bertujuan agar memudahkan guru dan siswa berkaitan dengan pemberian tugas, materi pembelajaran, serta komunikasi (diskusi) tanpa harus terikat waktu jam pelajaran di sekolah. Aplikasi 
ini juga memungkinan guru untuk memberikan nilai langsung terhadap tugas yang telah dikerjakan siswa melalui aplikasi tersebut.

Google Classroom memiliki keunggulan sebagai media yang terintegrasi dengan gmail, drive, youtube, dan aplikasi Google lainnya yang digunakan untuk melampirkan tugas yang dapat dilakukan dimanapun dan kapanpun dengan hanya mengakses Google Classroom secara daring.

Pada hasil penelitian yang dilakukan oleh Maulana Yusuf Aditya pada tahun 2018 dengan judul: "Penerapan Google Classroom pada Pembelajaran Bahasa Inggris di Lembaga Kursus Bahasa Inggris (e-home dan fun learning)", disimpulkan bahwa penerapan Google Classroom pada pembelajaran Bahasa Inggris sangat membantu tutor dalam menyampaikan materi pelajaran berbasis internet atau daring. Penggunaan aplikasi tersebut juga menarik minat siswa dan menjadikan mereka lebih aktif dan antusias karena pembelajaran menggunakan laptop dan smartphone sebagai sarana belajarnya. Hal senada juga dilakukan oleh Vicky dan Putri pada tahun 2016 tentang "Pembelajaran Blended Learning melalui Google Classroom di Sekolah Dasar. Hasil survey yang diperoleh yakni Penggunaan google classroom dapat memberikan akses terhadap siswa dalam melakukan pembelajaran secara daring. Guru dapat memberikan pembelajaran meskipun tidak di dalam kelas. Hal ini sebagai bentuk pengawasan guru terhadap siswanya ketika di luar sekolah.

Google Classroom juga memiliki kelebihan dibandingkan dengan aplikasi serupa lainnya. Selain sebagai media belajar berupa virtual class atau kelas maya, yang dapat mengundang siswa melalui kode pribadi kelas atau secara individu, Google Class juga bias digunakan sebagai alat keberhasilan pencapaian kelas. Keistimewaan lain dibanding aplikasi lainnya yaitu tidak terdapat pariwara atau iklan apapun di laman aplikasi ini yang mengganggu jalannya aktivitas penggunaan aplikasi tersebut.

Berikut adalah panduan menggunakan Google Classroom (https://www.classroom.hsks.sch.id/src/panduan_classroom_siswa.pdf $)$ :

1. How to Create Your Own Class

Click to go to Google classroom! Click go to classroom.

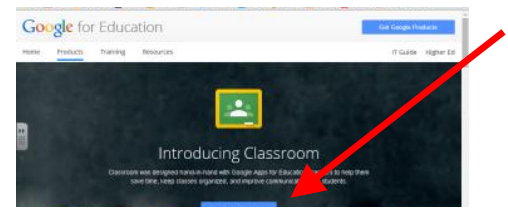

3

\section{Two Ways to Have Students Join}

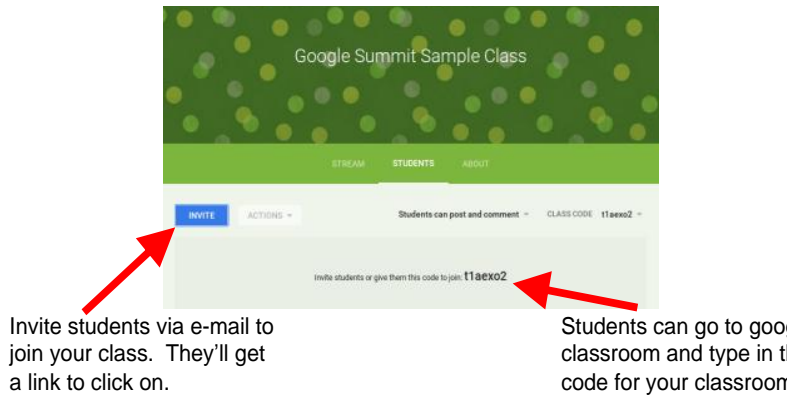

2. How to Create Your Own Class

Click on the Plus sign by your name and click create class. Type in your class name and section. Then click create.

4

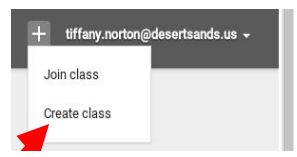

Using the Classroom Code to join:

1.Go to Google Classroom.

2.Click on the plus sign in the right hand

corner.

3.Click join class.
4. Then type in the

classroom code

and click join.

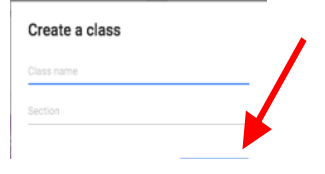


5.

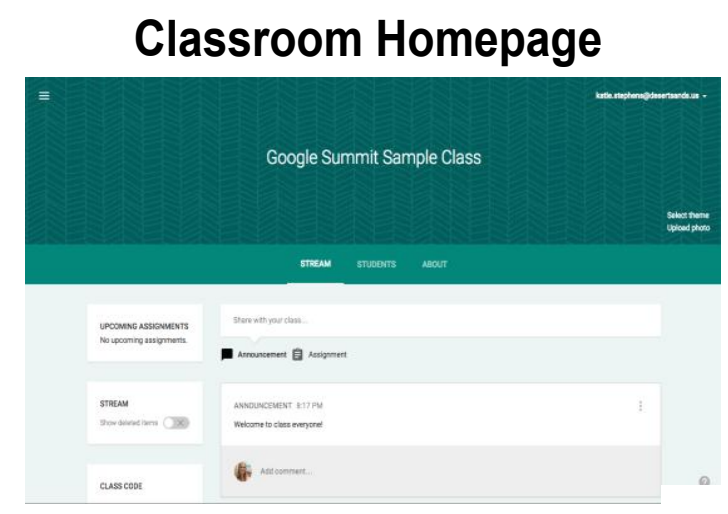

7.

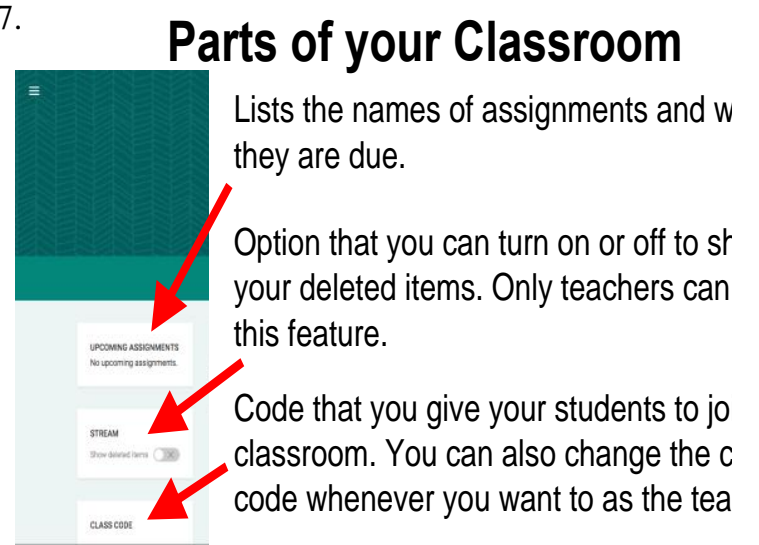

9.

\section{Parts of your Classroom}

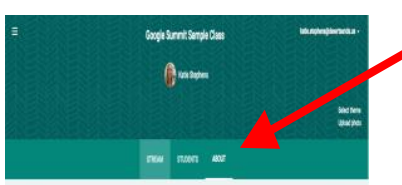

Change and edit the information about your classroom. Post links.

Invite more teachers to joil your classroom. *If you a teacher, they will be able do everything that you c's do, except delete the classroom.

11.

\section{What is an announcement?}

Google Classroom gives you a place to post your announcements.

Unlike a website with one way communication, studen can comment back on the announcement.

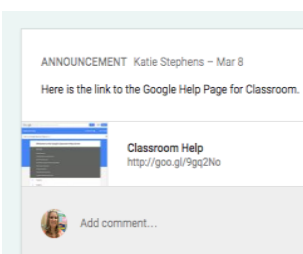

6.

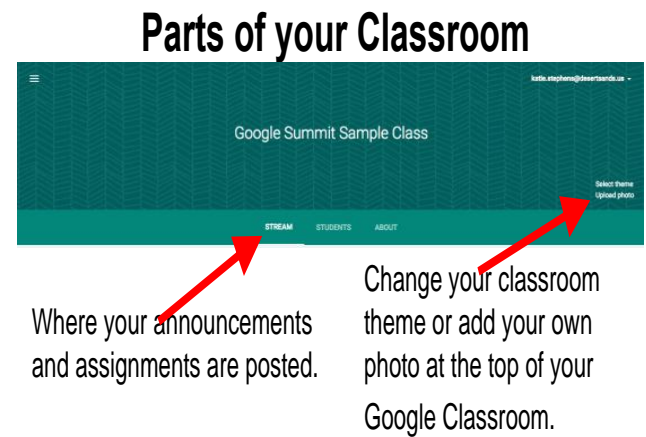

\section{Parts of your Classroom}

The students page is a list of all of the students enrolled in your classroom.

Can change the students abilities to post and comment in your classroom.

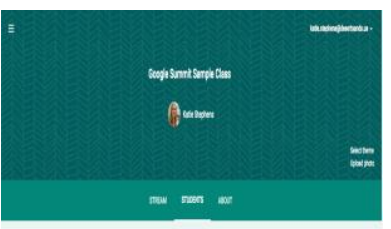

\section{$\checkmark$}
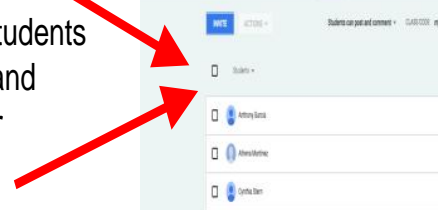

10.

The stream is where you will post your announcements and assignments.

When you create a new announcement or assignment it can save as a draft. So if you don't want to post it right away, you do not have to. It will save it for you to post later.

12.

\section{How to make an Announcement}
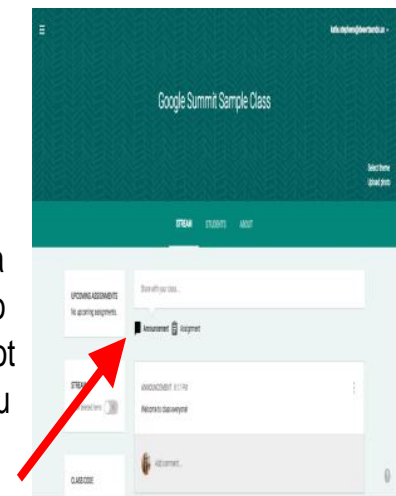

Click on announcement.

Type in your announcement into the top box.

You can add attachments, files from your drive, youtube links, or links to other sites.

Then click on the class that you want to post the announcement. You can post the same announcement to multiple classes at one time.

Then click post. 


\section{What is an assignment?}

Using Google Docs you no longer need to collect and pass out paper.

Google Classroom eliminates sharing issues by placing the document in the teacher and the students Google Drive immediately.

Students simply need to press the "turn in" button within Google Classroom to let the teacher know they are ready to have their work assessed.

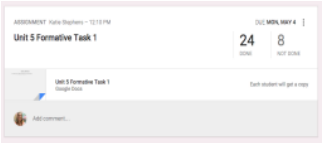

15.

How to make an Announcement

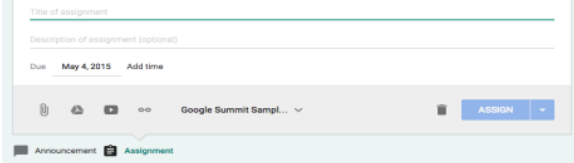

Click on assignment

Type in your title into the top box and add a description into the next box below.

You can add attachments. (See next slide).

Then select the due date.

Then choose the class that you want to post the assignment, you can post it to more than one classroom at the same time. Than nlink sccirn

17.

\section{Attaching Directly from Drive}

1.Click on the Drive icon

2.Search for your document in the window that pops up and click add

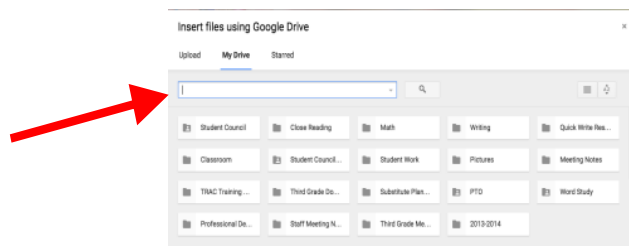

19.

\section{Tracking your students progress}

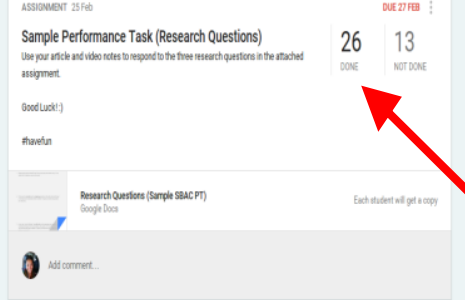

Easily see the number of studen who've completec and have yet to complete the give assignment.

\section{Ideas for using Assignments}

Collaborative Group Assignments

Individual Writing Assignments

Note taking templates

Tests and Quizzes

Test Prep

Project Based Learning
16.

\section{Attachment Options for Assignments}

1. Attach a document from your computer

2. Attach directly from your Google Drive

3. Attach a YouTube Video

4. Attach a Link
18.

\section{Choices when Attaching from drive}

1.Students Can View File

2.Students Can Edit File

3.Make a copy for each student

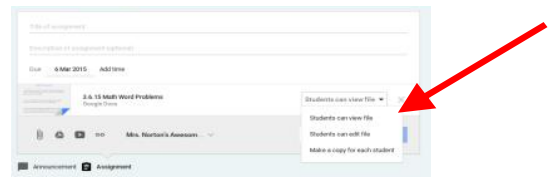

20.

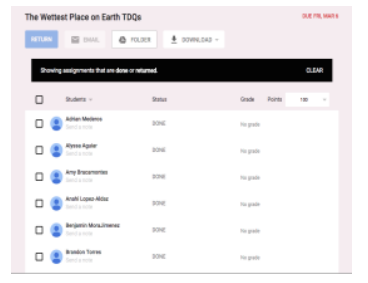

The detailed list of students who have completed their work.
The detailed list of students who have not completed their work.

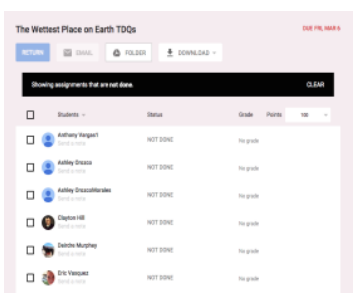


21.

\section{Adding a Co-Teacher}

-Multiple teachers can now serve as the admin for each Google Classroom

-Who would I add as a Co-Teacher? Intervention Specialists, Administration, Resource Teachers, Grade Level/Department Colleagues

\section{How to Add a Co-Teacher}

Adding a Co-Teacher

-Open up the class you want to use

this topic.
-Click "About"

-Click "Invite Teacher"

-Type in the email address of the coteacher
23.

\section{Archive a class}

-End of Quarter/Semester/Year

-Archiving preserves materials, discussions, and posts. The archived class is taken off of your home screen.

-All files are still available in Google Drive to view and edit
24.

\section{Archiving a Class}

-An archived class can be viewed by you and the students in the class.

-However, when the class is archived, you can't edit or add anything to the class until you restore it.

25

26

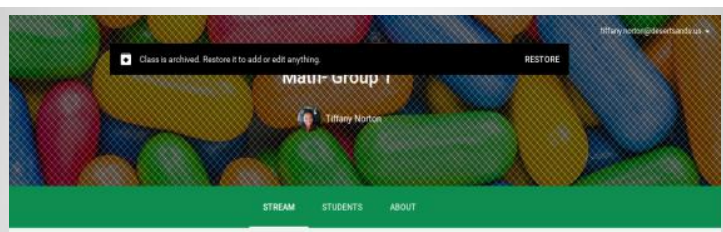

\section{How to Archive a Class}

-Click "Home"

-Click on the three dots next to the class name

-Click "Archive"

-When the 'Archive Class?' screen pops up,

click "Archive"

An Archived Classroom

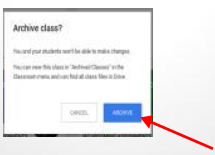

\section{Mobile APP}

-The mobile app allows students to do their work on any device.

-Perfect solution for classrooms that don't have 1:1 access, but have a BYOD policy

\section{Mobile App, cont.}

Students can:

-attach photos to assignments and posts

-attach images, PDFs, and web pages from other apps to their assignments

-work offline on items listed on the to do lists 
Berdasarkan latar belakang di atas, tim tergerak untuk melakukan sosialisasi bertemakan pembelajaran Blended Learning era revolusi 4.0 untuk para guru atau tenaga pengajar di YASPORBI III yang berlokasi di Pasar Minggu, Jakarta Selatan.

\section{METODE PELAKSANAAN}

Sasaran kegiatan pengabdian masyarakat yang berbentuk sosialisasi pembelajaran Blended Learning era revolusi 4.0 ini adalah untuk para guru atau tenaga pengajar di Yasporbi III, Pasar Minggu, Jakarta Selatan, khususnya bagi guru yang berorientasi terhadap kegiatan belajar berbasis daring atau online. Kegiatan sosialisasi ini akan dilakukan pada semester genap tahun ajaran 2019/2020.

Materi yang digunakan dalam sosialisasi ini dalah materi-materi yang berkaitan dengan blended learning, dalam hal ini khususnya Google Classroom. Beberapa prosedur pelaksanaan yang dilakukan dalam kegiatan sosialisasi ini adalah sebagai berikut:

1. Memberikan motivasi guna membangun semangat para guru agar lebih optimis, mandiri, kraetif, serta kompetitif dalam menghadapi tantangan era digital revolusi industry 4.0.

2. Memberikan sosialisasi berupa presentasi mengenai prosedur atau langkah-langkah penggunaan aplikasi Google Classroom dalam upaya peningkatan sumber daya pengajar terhadap pemanfaatan teknologi digital.

3. Melakukan presentasi dan memberikan penjelasan mengenai klasifikasi capaian aspek yang ditekankan.

4. Membimbing dan mendampingi para peserta sosialisasi dlam melakukan simulasi atau praktek penggunaan aplikasi Google Classroom dalam upaya pemanfaatan pembelajaran kelas maya berbasis internet.

5. Melakukan sesi tanya jawab berkenaan dengan kegiatan sosialisasi pengabdian kepada masyarakat bertemakan blended learning.

\section{HASIL DAN PEMBAHASAN}

Keberhasilan kegiatan sosialisasi pembelajaran bertemakan Blended Learning terutama pada aplikasi Google Classroom ini dapat dilihat dari rantusiasme peserta serta respon yang sangat baik mengenai kebermanfaatan materi dan kegiatan yang diberikan. Setelah kegiatan sosialisasi ini dilaksanakan, tim memberikan survey kepada para peserta untuk memilih empat kategori pilham respon yang terdiri dari: sangat bermanfaat, bermanfaat, kurang bermanfaat, dan sangat bermanfaat. Kemudian hasil survey tersebut yang berasal dari peserta dapat dilihat dari gambaran table berikut ini:

Tabel 1

Respon peserta mengenai kebermanfaatan kegiatan Pengabdian kepada Masyarakat di SD Yasporbi II Pasar Minggu

\begin{tabular}{ccc}
\hline No. & Kategori & Presentase \\
\hline 1. & Sangat bermanfaat & $82 \%$ \\
2. & Bermanfaat & $18 \%$ \\
3. & Kurang bermanfaat & 0 \\
4. & Tidak bermanfaat & 0 \\
\hline
\end{tabular}


Tabel di atas menunjukkan bahwa mayoritas peserta sosialisasi menyatakan bahwa kegiatan sosialisai ini sangat memberikan manfaat, yaitu sebnyak $82 \%$ dari totala keseluruhan peserta, dan sebanyak $16 \%$ menyatakan bahwa kegiatan ini bermanfaat. Kegiatan sosialisasi ini memberikan pengetahuan keoada seluruh peserta bahwa banyak sekali Learning Management System yang bisa digunakan untuk mendukung pembelajaran berbasis media digital bertemakan Blended Leaning yang sanagt sesuai dengan perkembangan era disruptif ini.

Para peserta yang dalam hal ini adalah para guru menyadari bahwa Blended Learning ini dibutuhkan sekali sebagai alternative pilihan media belajar dimana siswa sangat antusias belajar dengan menggunakan gadget atau perangkat digtal lainnya. Hal ini yang semakin memotivasi guru untuk senantiasa meng-upgrade pengetahuannya dalam bidang digital. Para guru amat sangat tertantang untuk menggunakan media aplikasi maupun platform berbasis internet dan interaktif.

Penyampaian materi serta prosedur yang diberikan oleh tim dirasa sangat baik oleh para peserta. Para guru sangat detail mengikuti kegiatan sosialisai ini dan menyatakan bahwa apa yang mereka terima amat sangat jelas, bisa dipahami secara gambling sehingga mereka bisa melakukan simulasi baik dengan cara dibimbing maupun melakukan praktek dengan sendirinya, para peserta sudah mampu mengoperasikan aplikasi Google Classroom mulai dari membuat akun, mengundang siswa, memberikan tugas, evaluasi, penilaian, serta jadwal remedial berdasarkan kode masing-masing kelas yang dibuatnya.

Melihat beberapa kondisi tersebut, dapat dikatakan bahwa program sosialisasi pembelajaran Blended Learning di SD Yasporbi III memberikan manfaat yang signifikan terhadap para peserta, yaitu guru-guru. Informasi yang disampaikan dalam kegiatan ini tidak hanya mampu meningkatkan kinerja guru dalam kegiatan belajar mengajar, namun juga dapat membantu proses kegiatan belajar non tatap muka yang tentu bisa dikontrol dan diawasi guru walaupun tidak ada di dalam kegatan tatap muka.

\section{SIMPULAN}

Sesuai dengan hasil yang diperoleh oleh tim, maka dapat disimpulkan bahwa:

1. Sosialisasi kegiatan Pengabdian kepada Masyarakat bertemakan Blended Learning memberikan pengaruh yang positif pada guru-guru SD Yasporbi III yang berlokasi di Pasar Minggu, Jakarta Selatan.

2. Secara keseluruhan, sosialisasi ini tidak hanya memberikan pengetahuan tentang penggunaan Learning Management System dan Blended Learning khususnya Google Classroom, namun juga secara umum dalam hal mempersiapkan media pembelajaran yang menarik, atraktif, dan uptodate.

\section{DAFTAR PUSTAKA}

Aditya, M.Y. 2018. Penerapan Google Classroom pada Pembelajaran Bahasa Inggris di Lembaga Kursus Bahasa Inggris (e-home dan fun learning) Kecamatan Bangkalan Kabupaten Bangkalan. Jurnal Elpeduaem Vol.4 no.4, Desember 2018. 
Maryani, Y. 2013. Aplikasi E-Learning Sebagai Model Pembelajaran Berbasis Teknologi informasi di Jurusan Kesehatan Gigi Poltekkes Kemenkes Pontianak. Vo. 9 No. 1 hal. 27-39.

Sjukur, S.B. 2012. Pengaruh Blended Learning terhadap Motivasi Belajar dan Hasil Belajar Siswa Tingkat SMK. Jurnal Pendidikan Vokasi, 3 (2), 368-378.

Wicaksono, V.D., \& Rachmadyanti, P. 2016. Pembelajaran Blended Learning melalui Google Classroom di Sekolah Dasar.Seminar Nasional Pendidikan PGSD UMS \& HDPGSDI Wilayah Jawa. 